\title{
ОСОБЕННОСТИ КОНТЕНТА ГАЗЕТЫ «КРАСНОЯРСКИЙ РАБОЧИЙ» ПО ПРОБЛЕМАМ ОСВОЕНИЯ АРКТИЧЕСКИХ ТЕРРИТОРИЙ КРАСНОЯРСКОГО КРАЯ В 1930-е ГГ.
}

\section{E.V. Polianskii}

\section{CHARACTERISTIC OF THE CONTENT OF THE NEWSPAPER «KRASNOYARSKIY RABOCHIY» ON THE RECLAIMING OF THE ARCTIC TERRITORIES OF THE KRASNOYARSK REGION IN THE 1930-S.}

Цель данной статьи - определение приоритетов и закономерностей контента, публикуемого в газете "Красноярский рабочий» в период активной популяризации арктической тематики в советской прессе и становления так называемого «полярного мифа». Актуальность данной темы обусловлена, с одной стороны, обозначившимся наступлением современного этапа интеграции арктических территорий Российской Федерации, характерного нарушением устоявшихся моделей организации пространства и принципов построения связей и взаимоотношений в социально-экономическом развитии зон Крайнего Севера. С другой стороны, экстенсивный характер освоения, сопровождающийся недостаточным уровнем проработки источниковой базы предыдущего периода, ведет к образованию известных пробелов в знании об особенностях советского опыта освоения Арктики. На основании фронтального и поверхностного тематического анализа нами был проведен обзор публикаций в газете «Красноярский рабочий» за период с 1932 по 1938 г., так или иначе посвященных теме освоения Севера. В результате, удалось условно разделить публикации на два периода: 1932- 1934 ге., 1934- 1938 ге. Отличительной особенностью первого явились: малое количество материалов, освящающих процесс освоения Арктики (менее $1 \%$ к общему количеству публикаций в газете) и их формальный и исключительно информационный характер. Формат статей - преимущественно короткие информационные заметки в несколько предложений. Особенность второго этапа, напротив, в количественном и качественном увеличении материалов о Севере. Газета «Красноярский рабочий» активно включиласъ в процесс оформления «полярного мифа», начало которому было положено так называемой «Челюскинской эпопеей» 1934 г. Публикуемые материалы пополняются крупными аналитическими статьями и материаламихрониками, растянутыми на несколько выпусков газеты. Практически для всех статей характерно наличие художественньх оборотов и возвышенных патетичных форм повествования, что сближает их с публицистикой. Несмотря на неинформативность материалов, про-

\section{4}




\section{Социально-экономический и әуманитарный журнал Красноярского ГАУ. 2019. № 4}

исходило выполнение следующих задач: популяризация Севера с целью привлечения наемной рабочей силы и проработка основнъх методов пропаганды и мифотворчества.

Ключевъге слова: Арктика, Красноярский край, ГУСМП, Красноярский рабочий, периодическая печать, освоение Севера, Челюскин, Енисейский север.

The purpose of this article is to define the content priorities and patterns of the newspaper «Krasnoyarskiy rabochiy» during the active popularization of Arctic topic in the Soviet press and the formation of the so-called «polar myth». On the one hand the relevance of this topic is due to the beginning of the modern stage of integration of the Russian Federation's Arctic territories, characterized by a disturbance in established models of space organization and the principles of building the relationships in the socio-economic development of the Far North. On the other hand the extensive nature of development, accompanied by an insufficient level of elaboration of the source base of the previous period, leads to the formation of well-known gaps in knowledge about the features of the Soviet experience in the development of the Arctic. We reviewed publications in the newspaper «Krasnoyarskiy rabochiy» from 1932 to 1938, which were devoted to the topic of development of the North, by frontal content analysis and thematic analysis. As a result we formally divided publications in two periods: 1932-1934 and 19341938. The hallmark of the first period was informative and formal character and fewer articles to the total volume of publications (less $1 \%$ ) - it was primary short informative notes in few sentences. The hallmark of the second period was quantitative and qualitative increase of the newspaper articles about the Arctic. Disaster by SS Chelyuskin in 1934 formed the basis of socalled «polar myth» and the newspaper «Krasnoyarskiy rabochiy» actively promoted the evolution of this myth. Published articles of that time were re plenished with analytical articles and chronicle that was published in the several issues of the newspaper. Most newspaper publications on this period had elements of imaginative literature and pathetic form of narrative that bring them together with journalism. Despite the lack of information publications of the newspaper «Krasnoyarskiy rabochiy» did two main tasks: they popularize the North to attract the labour force and elaborate the main methods of propaganda and myth making.

Keywords: Arctic, Krasnoyarsk Territory, GUSMP, Krasnoyarskiy rabochiy, periodicals, development of the North, SS Chelyuskin, Yenisei North.

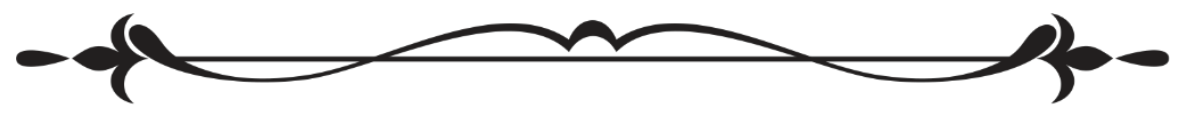

Практика освоения человеком «высоких широт» имеет многовековую историю. Однако роль России в изучении, колонизации и интеграции Арктики как неотъемлемой части страны насчитывает не более 200 


\section{Трибуна молодъхх ученьх}

лет, при том, что наиболее активная фаза освоения приходится на советский период отечественной истории. Особенно стоит отметить период 1930-х гг., явившийся переломным в отечественной практике освоения Заполярья. Именно в это время происходит качественное переосмысление стратегий и принципов интеграции Крайнего Севера в советское пространство.

За одно десятилетие арктические и субарктические территории нынешнего Красноярского края стали одним из центров советского экспорта, начался процесс строительства крупных городов в Арктике, закладывались основы для ее дальнейшего промышленного развития.

На этот же период приходится расцвет деятельности Главного управления Северного морского пути (ГУСМП, Главсевморпуть) - суперорганизации военно-мобилизационного характера, непосредственно ответственной за успехи советского строительства в Арктике [1, с. 8]. Фактически имевший полномочия отдельного наркомата [2, с. 37], подчинявшийся непосредственно СНК, Главсевморпуть контролировал всю территорию севернее 62-й параллели в азиатской части страны [3].

Несмотря на повышенный интерес к Северу в заявленный период и на деятельность такой крупной организации, как Главсевморпуть, на данный момент в научном знании образовалась лакуна в истории советского опыта освоения арктических широт. Особенно это прослеживается при изучении частных вопросов северного строительства, связанных с деятельностью организаций, ответственных за реализацию арктической политики. Сложившееся положение обусловлено, с одной стороны, обзорным характером многих работ, с другой - узостью источниковой базы, освещающей преимущественно события глобального и общесоветского характера. Именно поэтому необходимо включение в научный оборот местных источников, в особенности местной периодической печати.

В 1930-е гг. в северных районах Красноярского края выходило множество периодических изданий, в которых тема советского строительства в Арктике была центральной (например: «Большевик Заполярья», «Северная стройка», «Северный колхозник» и др.) либо занимала значительное место (см: «Речник Енисея», «Большевик Енисея», «Ударная вахта» и др.). Однако необходимо учитывать, что данные издания выходили преимущественно в северных районах и национальных округах, где количество населения было значительно ниже, чем население административного центра и юга Красноярского края [4, с. 2]. Таким образом, они не могли оказать влияние на формирование образа Крайнего Севера у подавляющего большинства населения региона. Газета «Красноярский рабочий», на начало 1930-х гг. - печатный орган горкома ВКП(б) [5, с. 2], горсовета и горпрофбюро ${ }^{1}$ г. Красноярска, являлась не только одним из старейших печатных изданий Сибири, но и имела го-

\footnotetext{
${ }^{1}$ Горпрофбюро - Городское профсоюзное бюро.
}

196 


\section{Социально-экономический и әуманитарный журнал Красноярского ГАУ. 2019. № 4}

раздо больший охват подписчиков. «Красноярский рабочий» имел не только информационную функцию, но и был одним из самых массовых средств пропаганды в крае. Исследователи часто обращаются к материалам газеты, как важному источнику по вопросам истории Красноярского края и его социально-экономического и культурного развития [5-8]. Однако статьи на тему освоения Арктики, помещенные в газете, не подвергались до сих пор качественному анализу.

Необходимо отметить, что в период с 1930 по 1934 г. «Красноярский рабочий» являлся окружной газетой Красноярского района ВосточноСибирского края. Таким образом, это несколько ограничивало количество тем, выносимых редакцией на повестку дня. К примеру, за 1932 г. в газете было опубликовано около десяти материалов, непосредственно посвященных теме Арктики в целом, и только четыре статьи, освещающих процесс хозяйственного освоения Енисейского Севера, т. е. менее одного процента к общему количеству публикуемой информации.

Материалы представлены преимущественно короткими информационными заметками-врезками, не раскрывающих сколь-нибудь подробно частных особенностей публикуемых новостей. Так, например, в заметке «В Красноярск прилетел Чухновский. Он держит путь на Игарку» в пяти предложениях раскрывается информация о времени прилета, технические особенности самолета, цели и задачи экспедиции и данные о направлении маршрута полета [9]. Несколько похожая по форме заметка «В Игарке будет построен 4-рамный лесозавод» была размещена в № 285 от 24.12.1932. Основное внимание в инфо-сводке уделяется вопросам производительности завода в приложении к потребностям экспорта, строительства в г. Игарка и развитию «рыбного хозяйства и зверобойной промышленности» [10].

Оставшиеся два материала представлены информационными статьями в форме обозрения. Первая посвящена необходимости проведения Карской морской научно-промысловой экспедиции с целью изучения возможности промышленного рыболовства в Енисейском заливе и прибрежных водах Карского моря. Автор достаточно критично отзывается о сложившимся положении в северном рыболовстве и заключает, что «нельзя в наше время, когда партия и правительство указывают на необходимость расширить рыбный промысел... сидеть с сетками и неводами у бережка и ждать, когда рыба сама соизволит подойти к рыбакам». Далее, отмечая сложности северного рыболовства, связанные с коротким навигационным периодом и общей неосвоенностью Таймыра, он переходит к описанию особенностей предстоящей экспедиции. Отдельно отмечено участие Комсевморпути ${ }^{2}$, Государственного океанографического института и Восточно-сибирской научной рыбохозяйственной

\footnotetext{
${ }^{2}$ Комсевморпуть - Комитет Северного морского пути. Основан при Сибревкоме 2 апреля 1920 г., с марта 1932 г. - Всесоюзное экспортно-импортное и транспортно-промышленное объединение [2, с. 54]. Упразднен в конце 1932 г. в связи с организацией Главного управления Северного морского пути с полной передачей полномочий последнему.
} 
станции. Материал заканчивается призывом ко всем организация Красноярска и Крайнего Севера о помощи в проведении работ [11].

Статья «Богатства недр Севера - социалистическим стройкам» от 18.08.1932 носит более критический характер. В начале обозрения помещена краткая историческая справка о развитии металлургии в районе норильского месторождения и отдельно отмечается роль революции 1917 г. в интенсификации работ в Норильске. Резюмируя необходимость улучшения качества работ, автор, отмеченный как «Бригада ЦК ЦМЗ (Цветметзолото $\left.{ }^{3} .-E . П.\right) »$, возлагает вину за данное положение на руководство Норильскстроя, обвиняя его в проволочках и «замораживании темпов» [12], чему посвящена 1/3 часть статьи.

Подобная скудость информации сохранялась вплоть до второй половины 1934 г. Так, за 1933 г. было опубликовано всего две информационных заметки. В первом полугодии 1934 г. не было выпущено ни одной статьи или инфо-сводки, затрагивающих вопросы северного строительства.

Качественное изменение ситуации происходит с июля 1934 г. Материалы начинают появляться практически в каждом выпуске. Интерес представляет блок инфо-сводок «По краю», размещенный в 153 номере от 06.07.1934, где 4 из 7 заметок посвящены строительству новых промышленных предприятий в г. Игарке и на о. Диксон [13]. Уже в конце месяца, в выпуске от 21.07.1934 4 из 10 заметок посвящены теме освоения Арктики [14], что примечательно, они были размещены в инфоблоке, озаглавленном как «Красноярск», т. е. окне, где преимущественно публиковалась информация о городских новостях. Это свидетельствует не только о возрастании важности данных событий, но и о попытке увеличения чувства причастности к ним у читателей газеты.

Активно рос объем информации об организации и ходе высокоширотных экспедиций, при обязательной ремарке о ведущей роли ГУСМП в их проведении. У газеты появляются спецкорреспонденты в лице непосредственных участников и руководителей экспедиционных групп $[15,16]$.

Новшеством стало появление крупных аналитических и обзорных статей на тему освоения Севера, а также интервью с непосредственными руководителями проектов строек и экспедиций. Например, в статье «Южно-Таймырская Пясинская экспедиция», опубликованной в выпуске от 10.07.1934, не просто рассказывается об особенностях проведения экспедиции и предстоящих работах, но и дается большая справка об истории хозяйственного использования реки Пясина. Работа экспедиции подается не иначе как «завоевание» с обязательным противопоставлением дореволюционному опыту, сопровождавшемуся неизбежным «вымиранием» аборигенного населения против «небывалого хозяйственного и культурного роста народностей Севера» в советский период [15].

\footnotetext{
${ }^{3}$ Цветметзолото - всесоюзное объединение, основанное в ноябре 1930 г., ответственное за добычу и разработку золотоносных и полиметаллических месторождений.
}

198 


\section{Социально-экономический и әуманитарный журнал Красноярского ГАУ. 2019. № 4}

Из статей практически исчезает критика в адрес организаций, непосредственно принимающих участие в процессе освоения Арктики. Если она и допускалась, то исходила либо от руководителей этих организаций, либо от представителей партии и правительства. Примерами могут служить статьи «Остров воздушных кораблей» от 15.08.1934 и «Завоевать передовые позиции в освоении Севера» от 27.07.1934 [17]. Примечательно, что последняя являлась по сути стенограммой речи М.О. Разумова, на тот момент Первого секретаря Восточно-Сибирского краевого комитета ВКП(б) [18], произнесенной на пятилетие г. Игарки.

Резкое увеличение количества материалов и повышение качества статей на тему освоения и хозяйственного использования Арктики (более 40 материалов только за второе полугодие 1934 г.) объясняется общим возрастанием интереса к арктической тематике в связи с походом «Челюскина» и так называемой «Челюскинской эпопеей» 4.

В конце февраля 1934 г. на первой полосе «Правды» помещается приветствие И.В. Сталина и членов Политбюро выжившим челюскинцам [19, с. 296], после чего следует резкое увеличение количества информации как в центральной, так и региональной прессе. Например, в «Красноярском рабочем» первая заметка о положении в лагере появляется уже 01.03.1934, и они продолжают публиковаться практически в каждом последующем номере. Информация о спасении и награждении выживших и летчиков-участников спасательной операции помещаются на первой странице районного издания. Освещение приезда челюскинцев в Красноярск и вовсе публикуется в виде передовицы [20].

Именно в это время происходит конструирование «полярного мифа». Процесс освоения уподобляется военным действиям и «войне с ледяной пустыней» $[19$, с. 298; 21], как следствие, не удивительно использование таких оборотов, как «завоевание Арктики». Совместно с этим происходил и процесс мифологизации самих полярников ${ }^{5}$, доходя до крайности в статье «Изучить жизнь полярного человека» [22], где под «полярным человеком» подразумевается не аборигенное население Севера, а непосредственно полярники. Фактически, автор статьи на основании поверхностных медико-физических данных противопоставляет «жителя севера» «жителю юга» не просто в культурно-социальном, но на биологическом уровне. При ведущей роли ГУСМП и лично ее руководителя О.Ю. Шмидта в проведении экспедиции «Челюскина» понятно отсутствие критической оценки работы данной организации и предприятий, ей подведомственных.

\footnotetext{
${ }^{4}$ Пароход «Челюскин» - советский пароход, построен в Дании в 1933 г. Именно он был выбран для прохождения Северного морского пути в одну навигацию на судне не ледокольного типа. Последовавшие события, такие как гибель теплохода и ледяной дрейф участников экспедиции, стали известны как «Челюскинская эпопея», а члены экспедиции стали именоваться как «челюскинцы».

${ }^{5}$ Полярник - участник полярных экспедиций, исследователь полярных стран.
} 
К концу 1934 г. количество публикуемой информации о Севере несколько сокращается. Связано это, прежде всего, с убийством С.М. Кирова, что создало новый крупный инфо-повод, которому в газете уделялось чрезвычайное внимание, несколько сместившее расстановку приоритетов в публикациях. Однако образование Красноярского края в декабре 1934 г. привело к тому, что «Красноярский рабочий» становится главным региональным изданием оргбюро ЦК ВКП(б), оргкомитета ВЦИК Красноярского края и Красноярского горкома ВКП(б), что существенно повышало количество и качество статей, так как не освещать события, происходящие на севере региона, издание больше не могло.

Уже в номере от 04.01.1935 публикуется крупный материал «Эвенки» - обширная обзорная статья, раскрывающая особенности жизни и процесс интеграции эвенков в советское общество. Примечательно, что это первый материал об Эвенкии и ее населении, размещенный в газете. Структурно статья напоминает множество других обзорных статей и делится на подтемы: прежде всего дается популярная историческая справка с обязательным противопоставлением дореволюционного и советского опыта освоения. Далее практически вся статья посвящена особенностям и успехам организации советского быта местного населения, политической работе и развитию сельского хозяйства [23]. В целом данный материал можно считать показательным в плане произошедшего смещения акцентов с описания частных технических особенностей экспедиций и природных условий территории в сторону описания социального строительства, политической работы и улучшения быта населения Крайнего Севера. «Построим дома и в тундре», «В Игарке начался посев огурцов», «Образцовая школа», «Избирательные документы для Крайнего Севера», «Октябрьские дни на острове Диксон», «Сельское хозяйство в Туруханском крае» - вот далеко неполный, но показательный список статей. Таким образом продвигалась идея о завершении стадии «покорения» высоких широт, сменившаяся стадией культурного строительства и улучшений условий быта жителей Енисейского Севера.

Продолжалась публикация материалов о планируемых и проведенных экспедициях. Особое внимание уделялось Пясинским и Карским экспедициям, именовавшимся не иначе как «операции» (см. например [24-26]), что сближало их с формой военных действий. Публиковалось большое количество информации, поступающей из г. Игарки, и в целом этому городу уделяется повышенное внимание на страницах газеты. Так, материал «Город солнца» от 29.05.1936 является библиографической статьей, рассматривающей публикации об Игарке, размещенные в № 6 журнала «Советская Арктика» за 1936 г. [27].

Определенный интерес представляют две статьи из 112 и 113 номеров газеты за 1936 г., посвященные аварии самолета Н-125 под руководством Т.Л. Петрова в таймырской тундре. В статье «Трое в тундре» обращает на себя внимание художественный характер данного публицистического очерка. Выделяются главные и второстепенные герои, опи- 


\section{Социально-экономический и әуманитарный журнал Красноярского ГАУ. 2019. № 4}

сываются их особенности и роли в лагерной жизни, так, бортмеханик Игнатьев получает роль охотника и только в таком качестве упоминается по тексту. Пилот самолета М.В. Линдель, получив «по единодушному определению двух остальных» членов команды прозвище «повар второй руки» за свои сомнительные кулинарные качества, далее по тексту обязательно упоминается с припиской данного прозвища [28].

Статья «Из плена тундры» логически продолжала тему спасения пилотов самолета Н-125, только уже от лица спасателя - полярного летчика П.Г. Головина. Данный материал был посвящен процессу спасения и вывоза пострадавших в г. Красноярск, он также имел художественную экспрессивную окраску: «Радость встречи была велика, но сантиментами заниматься было некогда, погода торопила нас в дальнейшее путешествие» [29]. После челюскинской эпопеи «советских читателей накрывает волна полярной литературы», не просто имевшей колоссальный успех у читателя, но и выделившейся в отдельный поджанр [21], чем и объясняется не только стилистический выбор авторов статьи, но и выбор редакции в размещении данного материала, по сути необязательного.

Похожи по структуре статьи о доставке избирательных документов для жителей Крайнего Севера экипажем под руководством летчика В.П. Смирнова в 1937 г. Повествование превращается в целую хронику, от короткой информационной заметки в 240 номере через развернутое описание условий полета, которому посвящена практически вся 4 страница номера 243 [30, 31], к монологу-воспоминанию полярного летчика Я.С. Липпа о становлении полярной авиации на Енисее [32].

Крупными инфо-поводами явились поиски пропавшего экипажа С.А. Леваневского в 1937 г. и возвращение зимовщиков дрейфующей полярной станции «Северный полюс-1» в 1938 г. Примечательно, что проблемы навигации 1937- 1938 гг., в результате которой практически весь ледокольный флот ГУСМП был вынужден зазимовать во льду, редакцией не освещаются, кроме ряда заметок об окончании операции по выводу зимовавших судов в 207 номере газеты [33], несмотря на то, что именно это событие во многом послужило причиной пересмотра арктической политики и привело к реорганизации Главного управления Северного морского пути.

Таким образом, нельзя сказать, что материалы, опубликованные в газете «Красноярский рабочий» в период с 1932 по 1938 г., являются показательными и всеобъемлющими в вопросе об истории освоения арктических широт в рассматриваемый период. Как исторические источники они не являются ни независимыми, ни универсальными. Становление и эволюция полярной тематики в советской прессе, неизменно заслуживавшей внимание читателей, предопределили факт размещения на страницах газеты статей на тему Севера, по сути необязательных и неинформативных, несущих развлекательно-популяризационный и 


\section{Трибуна молодьх ученьх}

пропагандистский характер. В результате происходило выполнение двух главных задач:

1. Привлечение наемной рабочей силы на Север края, так как ГУСМП в своей деятельности был ограничен в возможности использования принудительного труда.

2. Разработка и «обкатка» основных приемов и механизмов мифологизации и пропаганды, которые в дальнейшем активно будут воспроизводиться при создании мифов про стахановское движение, армию и космос.

Безусловно, что материалы и статьи, помещенные на страницах газеты «Красноярский рабочий», являются важным источником не только по истории освоения Енисейского Севера, но и по созданию социальной памяти населения о северном строительстве, и требуют дальнейшего углубленного и качественного изучения.

\section{Литература}

1. Элерт A.X., Тимошенко А.И. Россия в Арктике: проблемы изучения исторического опыта освоения территории // Гуманитарные науки в Сибири. - 2016. - № 3. - С. 5- 12.

2. Карские операции 1920-1930-х годов: сб. документов из архива компании «Совфрахт» / сост. М. Емелина, М. Савинов, П. Филин. - М.: Паулсен, 2019. - 296 с.

3. Положение о Главном управлении Северного морского пути при СНК Союза ССР: постановление СНК от 22.06.1936. - URL: www.consultant.ru.

4. Сибирский край: стат. справочник. - Новосибирск, 1930. - 805 с.

5. Макаров A.A. Периодическая печать в процессе агитационнопропагандистского обеспечения массовых репрессий 1934-1938 гг. (на материалах Красноярского края) // Известия Алтайского государственного университета. - 2007. - № 4-2. - С. 102- 105.

6. Бершадская C.B. «Красноярский рабочий» о проблемах развития народного образования в Красноярском округе в 1921- 1926 гг. // Гришаевские чтения: мат-лы I национ. науч. конф., посвящ. памяти д-ра ист. наук, проф., заслуженного работника высшей школы Василия Васильевича Гришаева / Краснояр. гос. аграр. ун-т. - Красноярск, 2018. - С. 118- 125.

7. Бершадская С.В., Айснер Л.Ю. Развитие системы просвещения в г. Красноярске в 1921- 1926 гг. (на материалах газеты «Красноярский рабочий») // Современные исследования социальных проблем. 2018. - № 1. - C. 139- 151.

8. Дементъев А.П. Союз леворадикальных сил в Красноярске (март 1917 г. - июнь 1918 г.) // Вестник КрасГАУ. - 2013. - № 6. - С. 203209.

9. В Красноярск прилетел Чухновский. Он держит путь на Игарку // Красноярский рабочий. - 1932. - № 109 (4140). - С. 2. 


\section{Социально-экономический и әуманитарный журнал Красноярского ГАУ. 2019. № 4}

10. В Игарке будет построен 4-рамный лесозавод // Красноярский рабочий. - 1932. - № 285 (4316). - С. 2.

11. Никитинский B. Карская морская научно-промысловая экспедиция // Красноярский рабочий. - 1932. - № 147 (4178). - С. 2.

12. Богатства недр Севера - социалистическим стройкам. Норильск требует широкого внимания и помощи // Красноярский рабочий. 1932. - № 182 (4213). - С. 2.

13. По краю // Красноярский рабочий. - 1934. - № 151 (4774). - С. 2.

14. Красноярск // Красноярский рабочий. - 1934. - № 167 (4790). - С. 2.

15. Кублицкий Г. Южно-Таймырская Пясинская экспедиция // Красноярский рабочий. - 1934. - № 156 (4779). - С. 4.

16. Иванов А.Д. Образцово подготовиться к Пясинской // Красноярский рабочий. - 1934. - № 280 (4903). - С. 5.

17. Бегичев C. Остров воздушных кораблей // Красноярский рабочий. 1934. - № 186 (4809). - С. 3.

18. Разумов М.О. Завоевать передовые позиции в освоении Севера // Красноярский рабочий. - 1934. - № 170 (4793). - С. 2.

19. Алиев P.A. Изнанка белого. Арктика от викингов до папанинцев. М.: Паульсен, 2016. - 408 с.

20.Да здравствуют наши челюскинцы! // Красноярский рабочий. 1934. - № 170 (4793). - С. 1.

21. Турков A.A. Челюскинская эпопея 1934 года как ключевой элемент советской пропаганды освоения Арктики // Вестник Рязанского государственного университета им. С.A. Есенина. - 2017. - № 2. - URL: https:// elibrary.ru/item.asp?id=29273625.

22. Изучить жизнь полярного человека. Новая медицинская экспедиция на Енисейский север // Красноярский рабочий. - 1934. - № 164 (4787). - С. 4.

23. Сибирцев Эвенки // Красноярский рабочий. - 1935. - № 4 (4926). C. 2.

24.Добровольский В.А. Пясинские поход // Красноярский рабочий. 1936. - № 118 (5341). - С. 3.

25. Шухер А. Пясинская операция // Красноярский рабочий. - 1937. № 230 (5754). - С. 4.

26.Лесной экспорт Красноярского края // Красноярский рабочий. 1937. - № 230 (5754). - C.2.

27. Город солнца // Красноярский рабочий. - 1936. - № 122 (5354). С. 3.

28.Стаккатов A. Трое в тундре // Красноярский рабочий. - 1936. № 112 (5335). - C. 3.

29. Юдина Б. Из плена тундры // Красноярский рабочий. - 1936. - № 113 (5336). - С. 3.

30.Избирательные документы для Крайнего Севера // Красноярский рабочий. 1937. - № 240 (5764). - С. 4. 
31. Смирнов В.П., Ванюшин С.П., Липп Я.С. Отважный рейс // Красноярский рабочий. - 1937. - № 243 (5767). - С. 4.

32.Липn Я.С. Под крылом самолета // Красноярский рабочий. - 1937. № 257 (5781). - С. 3.

33. Операция вывода зимовавших судов закончена // Красноярский рабочий. - 1938. - № 207 (6032). - С. 3.

\section{Literatura}

1. Jelert A.H., Timoshenko A.I. Rossija v Arktike: problemy izuchenija istoricheskogo opyta osvoenija territorii // Gumanitarnye nauki v Sibiri. 2016. - № 3. - S. 5- 12.

2. Karskie operacii 1920-1930-h godov: sb. dokumentov iz arhiva kompanii «Sovfraht» / sost. M. Emelina, M. Savinov, P. Filin. - M.: Paulsen, 2019. - 296 s.

3. Polozhenie o Glavnom upravlenii Severnogo morskogo puti pri SNK Sojuza SSR: postanovlenir SNK SSSR ot 22.06.1936. - URL: www.consultant.ru.

4. Sibirskij kraj: stat. spravochnik. - Novosibirsk, 1930. - 805 s.

5. Makarov A.A. Periodicheskaja pechat' $\mathrm{v}$ processe agitacionnopropagandistskogo obespechenija massovyh repressij 1934-1938 gg. (na materialah Krasnojarskogo kraja) // Izvestija Altajskogo gosudarstvennogo universiteta. - 2007. - № 4-2. - S. 102- 105.

6. Bershadskaja S.V. «Krasnojarskij rabochij» o problemah razvitija narodnogo obrazovanija v Krasnojarskom okruge v 1921-1926 gg. // Grishaevskie chtenija: mat-ly I nacion. nauch. konf., posvjashh. Pamjati d-ra ist. nauk, prof., zasluzhennogo rabotnika vysshej shkoly Vasilija Vasil'evicha Grishaeva / Krasnojar. gos. agrar. un-t. - Krasnojarsk, 2018. - S. 118- 125.

7. Bershadskaja S.V., Ajsner L.Ju. Razvitie sistemy prosveshhenija v g. Krasnojarske v 1921-1926 gg. (na materialah gazety «Krasnojarskij rabochij») // Sovremennye issledovanija social'nyh problem. - 2018. № 1. - S. 139- 151.

8. Dement'ev A.P. Sojuz levoradikal'nyh sil v Krasnojarske (mart 1917 g. ijun' 1918 g.) // Vestnik KrasGAU. - 2013. - № 6. - S. 203- 209.

9. V Krasnojarsk priletel Chuhnovskij. On derzhit put' na Igarku // Krasnojarskij rabochij. - 1932. - № 109 (4140). - S. 2.

10. V Igarke budet postroen 4-ramnyj lesozavod // Krasnojarskij rabochij. 1932. - № 285 (4316). - S. 2.

11. Nikitinskij V. Karskaja morskaja nauchno-promyslovaja jekspedicija // Krasnojarskij rabochij. - 1932. - № 147 (4178). - S. 2.

12. Bogatstva nedr Severa - socialisticheskim strojkam. Noril'sk trebuet shirokogo vnimanija i pomoshhi // Krasnojarskij rabochij. - 1932. № 182 (4213). - S. 2.

13. Po kraju // Krasnojarskij rabochij. - 1934. - № 151(4774). - S. 2.

14. Krasnojarsk // Krasnojarskij rabochij. - 1934. - № 167 (4790). - S. 2. 


\section{Социально-экономический и әуманитарный журнал Красноярского ГАУ. 2019. № 4}

15. Kublickij G. J uzhno-Tajmyrskaja Pjasinskaja jekspedicija // Krasnojarskij rabochij. - 1934. - № 156 (4779). - S. 4.

16. Ivanov A.D. Obrazcovo podgotovit'sja k Pjasinskoj // Krasnojarskij rabochij. - 1934. - № 280 (4903). - S. 5.

17. Begichev S. Ostrov vozdushnyh korablej // Krasnojarskij rabochij. 1934. - № 186 (4809). - S. 3.

18. Razumov M.O. Zavoevat' peredovye pozicii v osvoenii Severa // Krasnojarskij rabochij. - 1934. - № 170 (4793). - S. 2.

19. Aliev R.A. Iznanka belogo. Arktika ot vikingov do papanincev. - M.: Paul'sen, 2016. - $408 \mathrm{~s}$.

20.Da zdravstvujut nashi cheljuskincy! // Krasnojarskij rabochij. - 1934. № 170 (4793). - S. 1.

21. Turkov A.A. Cheljuskinskaja jepopeja 1934 goda kak kljuchevoj jelement sovetskoj propagandy osvoenija Arktiki // Vestnik Rjazanskogo gosudarstvennogo universiteta im. S.A. Esenina. - 2017. - № 2. - URL: https:// elibrary.ru/item.asp?id=29273625.

22. Izuchit' zhizn' poljarnogo cheloveka. Novaja medicinskaja jekspedicija na Enisejskij sever // Krasnojarskij rabochij. - 1934. - № 164 (4787). - S. 4.

23. Sibircev J evenki // Krasnojarskij rabochij. - 1935. - № 4 (4926). - S. 2.

24. Dobrovol'skij V.A. Pjasinskie pohod // Krasnojarskij rabochij. - 1936. № 118 (5341). - S. 3.

25. Shuher A. Pjasinskaja operacija // Krasnojarskij rabochij. - 1937. № 230 (5754). - S. 4.

26. Lesnoj jeksport Krasnojarskogo kraja // Krasnojarskij rabochij. - 1937. № 230 (5754). - S.2.

27. Gorod solnca // Krasnojarskij rabochij. - 1936. - № 122 (5354). - S. 3.

28. Stakkatov A. Troe v tundre // Krasnojarskij rabochij. - 1936. - № 112 (5335). - S. 3.

29.J udina B. Iz plena tundry // Krasnojarskij rabochij. - 1936. - № 113 (5336). - S. 3.

30.Izbiratel'nye dokumenty dlja Krajnego Severa // Krasnojarskij rabochij. 1937. - № 240 (5764). - S. 4.

31. Smirnov V.P., Vanjushin S.P., Lipp Ja.S. Otvazhnyj rejs // Krasnojarskij rabochij. - 1937. - № 243 (5767). - S. 4.

32. Lipp Ja.S. Pod krylom samoleta // Krasnojarskij rabochij. - 1937. № 257 (5781). - S. 3.

33. Operacija vyvoda zimovavshih sudov zakonchena // Krasnojarskij rabochij. - 1938. - № 207 (6032). - S. 3. 